\title{
Colombia: entre la guerra y la paz*
}

YESID REYES ALVARADO**

\section{RESUMEN}

La historia de la lucha armada en Colombia y de los varios intentos que se han hecho para conseguir la paz muestra que las causas de nuestros conflictos han sido diversas, que la lucha guerrillera ha cambiado con el transcurso de los años y que, por consiguiente, sólo se puede hacer la paz si se tienen en cuenta las razones de fondo que dieron origen a la lucha armada y se le busca una adecuada solución. Los problemas meramente técnico-jurídicos, como el alcance del concepto de delito político, la determinación de los delitos conexos que puedan ser objeto de una amnistía o la competencia de la Corte Penal Internacional, son relativamente sencillos de superar. Pero si no se eliminan o morigeran las causas que han dado origen a los actuales grupos guerrilleros y paramilitares, las amnistías sólo conseguirán una momentánea disminución cuantitativa del problema, pero no lograrán que los grupos alzados en armas desaparezcan del escenario nacional.

\section{PALABRAS CLAVE}

Lucha armada, violencia política, procesos de paz, amnistía e indulto.

El texto del presente artículo corresponde, en lo sustancial, a una conferencia dictada por el autor en la Universidad de Castilla La Mancha (Toledo), en desarrollo de los cursos internacionales correspondientes a enero de 2004.

Docente Universitario. Abogado, Universidad Externado. 


\section{ABSTRACT}

The history of the armed warfare and of the several attempts that had been done in order to get the peace in Colombia, show us that the causes of our conflicts had been diverse and that the insurgent warfare had changed with the years, consequently, the peace only can be reached if the deep reasons that were the source of the armed warfare are taken into account and an adequate solution is sougth for them. The issues of merely legal technic like the scope of the concept of Political Crime, the determination of the connected offenses that could be object of an Amnesty or the competence of the International Criminal Court, are relatively easy to surmount, but if the causes that had been the origin of the present insurgent groups, are not eliminated or moderated, the amnesties only will get a momentary quantitative decrease of the problem , but they will not get that the rebel groups disappear from the National stage.

\section{INDEX TERMS}

Armed warfare, politic violence, peace process, amnesty and pardon.

En agosto de 2003 el Ministro del Interior colombiano presentó a consideración del Parlamento un proyecto de ley "por la cual se dictan disposiciones en procura de la reincorporación de miembros de grupos armados que contribuyan de manera efectiva a la consecución de la paz nacional". De esta manera tituló el gobierno coIombiano una propuesta legislativa con la que se busca dar inicio a un proceso de paz con los grupos alzados en armas que actualmente operan en el territorio nacional. No es ésta, sin embargo, la primera vez que en Colombia se intenta un proceso de paz; por el contrario, en su corta historia ha ido acumulando una larga experiencia en procesos de paz, quizá porque también tiene una larga experiencia en conflictos armados.

Desde el descubrimiento mismo de América, los conquistadores se enfrentaron militarmente a los indígenas en una prolongada guerra que, de cuando en cuando, era interrumpida para dar paso a la vigencia de acuerdos de paz que, por lo general, consistían en exigir a los indígenas el abandono de las armas y su confinamiento en zonas específicas del territorio conquistado; como quiera que esas condiciones suponían para los aborígenes ser desplazados de sus tierras y forzados a vivir en los sitios de menor productividad agrícola o ganadera, los períodos de paz resultaban efímeros. Los enfrentamientos fueron llegando a su fin, bien por la exterminación casi absoluta de los indígenas, como ocurrió en Norteamérica, o por la paulatina incorporación de los aborígenes supervivientes a la cultura dominante, como sucedió en algunos países de Suramérica, en los que la mezcla de razas contribuyó a ese propósito.

En la época de la Colonia, hubo en Colombia varios movimientos populares en contra del gobierno español, siendo uno de los más destacados el que se conoció como la Revolución de los Comuneros, nombre con el que se ponía de presente que la gente "del común" se había alzado contra el poder político virreinal que entonces detentaba el poder. Cuando los Comuneros se aprestaban a ingresar a Bogotá, el gobierno español los persuadió de la necesidad de deponer las armas y consiguió la disolución del movimiento a cambio de promesas sobre la derogatoria de los gravámenes impuestos por la Coro- 
na. Dispersados los revolucionarios, el gobierno aprehendió a sus líderes, los ejecutó y procedió a descuartizar sus cuerpos para exhibir separadamente sus cabezas, sus extremidades y sus troncos en las plazas de los pueblos donde había tenido origen la rebelión.

Después de un primer y corto intento de independencia, arribó a lo que hoy es Colombia Don Pablo Morillo, quien con el título de "El Pacificador" fue enviado por la Corona española para someter nuevamente a los criollos americanos que por la vía de las armas se habían tomado el poder en ese virreinato. La reconquista del poder se produjo con relativa facilidad y estuvo marcada por una sangrienta represión contra quienes habían tomado parte en la lucha por la independencia; esta nueva situación condujo a la reorganización de la lucha por parte de reductos de resistencia que habían quedado en los Llanos de Colombia y Venezuela, alrededor de los cuales se organizó y dio inicio a la gesta libertadora acaudillada por Simón Bolívar, que finalmente obtuvo la independencia definitiva por la vía armada.

Al asumir el gobierno Bolívar, defendió la implantación del centralismo, la configuración de un ejecutivo fuerte frente al legislativo, la existencia de libertades moderadas y el respeto a los postulados de la iglesia católica. En contra de estas tesis se pronunció otro de los líderes de la independencia, el general Francisco de Paula Santander, para quien el país debería organizarse como una federación, el ejecutivo debería tener menos poder, los ciudadanos deberían disponer de libertades absolutas y el Estado debería ser laico. Para algunos, estas dos concepciones sobre la configuración del Estado dieron ori- gen en Colombia a los dos partidos políticos que desde entonces dominan la vida política del país: el partido conservador, que decía seguir las tesis de Simón Bolívar y el partido liberal que afirmaba ser fiel a los planteamientos de Francisco de Paula Santander ${ }^{1}$.

El enfrentamiento de los partidarios de estas dos formas de gobierno desembocó en una sucesión de guerras civiles que, con diferente intensidad, se prolongaron desde poco después de la Guerra de Independencia, en la primera parte del siglo XIX, hasta los albores del siglo XX. Como resultado de las mismas, el partido conservador logró acceder al poder desde 1885 y lo mantuvo de manera ininterrumpida hasta 1930, momento en el que, debido a una división interna, perdió las elecciones frente al partido liberal que asumió y mantuvo el poder hasta 1946, año en el que los conservadores retornaron al poder gracias a la división interna del liberalismo entre "gaitanistas" (partidarios del caudillo Jorge Eliécer Gaitán) y "turbayistas" (seguidores del candidato Gabriel Turbay).

El gobierno conservador que se instala en 1946 cuenta con personas influenciadas por el fascismo italiano y el franquismo español, que propugnan por un severo recorte de las libertades individuales. Ante el surgimiento de una resistencia armada del campesinado liberal contra la violencia oficial, el ministro del interior de la época manifestó públicamente que el gobierno impondría la autoridad en el territorio nacional "a sangre y fuego". Conscientes de que su acceso al poder había sido producto de la división liberal, pues los votos de los dos candidatos liberales a la presidencia superaban ampliamente los obtenidos por el conservatismo, algunos dirigen-

Sin embargo, hay quienes sostienen que los partidos conservador y liberal no tuvieron su origen en los ideales de BOLÍvAR y SANTANDER; en defensa de esta tesis suele decirse, entre otras cosas, que en el atentado de que fue víctima el Libertador en la famosa "noche septembrina", participaron personas como MARIANO OSPINA RODRÍGUEZ, quien posteriormente tomó parte en la fundación oficial del partido conservador. 
tes de esta última colectividad empezaron a fomentar la lucha partidista para tratar de impedir que el liberalismo obtuviera una nueva victoria en las elecciones de 1950. Laureano Gómez, uno de los líderes del partido conservador, denunció que el triunfo electoral de los liberales había sido conseguido gracias a la falsificación de 1.800.000 documentos de identidad, acusación con la que avivó el enfrentamiento entre liberales y conservadores. Paralelamente, el gobierno reclutó en un municipio de Boyacá grupos de policía especialmente violentos, que reprimieron brutalmente cualquier brote de inconformidad y que fueron tristemente célebres con el nombre de "policía chulavita", denominación con la que se hacía referencia a la población de donde era originarios (Chulavita) y a su vinculación con los cuerpos oficiales de policía.

En medio de ese escenario político, empezó a destacarse la figura de un abogado liberal, discípulo de Enrico Ferri en Italia, quien como candidato liberal a la presidencia de la República se definió como un hombre del pueblo que luchaba contra la oligarquía gobernante; con sus encendidos discursos, Jorge Eliécer Gaitán despertó en el pueblo la conciencia de clase y obtuvo un enorme respaldo popular que utilizó para oponerse al gobierno con multitudinarias manifestaciones, marchas por la paz y la reivindicación de derechos y libertades a favor del pueblo. El 9 de abril de 1948, fue asesinado en Bogotá Jorge Eliécer Gaitán, el único político que por aquella época representaba clara y públicamente la inconformidad popular; su presunto asesino fue retenido y linchado por una turba enfurecida que arrastró su cadáver hasta el palacio de gobierno, incendiando y saqueando a su paso despachos judiciales, oficinas públicas y locales comerciales. Durante varios días la situación fue incontrolable en varios municipios del país, especialmente en Bogotá donde los incendios crecían de manera incontrolada en el centro de la ciudad, los francotiradores abundaban y un sector de la policía (de extracción predominantemente liberal) se negaba a enfrentarse a los sublevados; el gobierno, por su parte, había conseguido reunir dentro del ejército tropas leales que marcharon desde el vecino departamento de Boyacá hacia Bogotá y consiguieron controlar la insurrección popular.

Mientras los sublevados exigían la renuncia de presidente y la asunción del gobierno por parte del liberalismo, los conservadores se negaban a abandonar el poder y amenazaban con sofocar militarmente la rebelión; proponían, en cambio, permitir el ingreso del partido liberal al gobierno mediante la designación de varios ministros en el gabinete, propuesta que finalmente fue acepada por el liberalismo, en una actitud que puede ser vista hoy como un gesto de perdón público frente a los desmanes gubernamentales que hasta ese momento habían venido denunciando.

Sin embargo, la tensión entre liberales y conservadores no terminó, pese al ingreso de figuras del partido liberal al gabinete ministerial; mientras aquéllos exigían el adelantamiento de las elecciones, confiados en que gracias a sus mayorías electorales obtendrían el triunfo, los conservadores insistían en que esa mayoría estaba cimentada sobre documentos de identidad falsificados por los liberales. Buena parte de los parlamentarios, liberales y conservadores, acudían armados a las sesiones del Congreso, una de la cuales terminó con un enfrentamiento a bala que costó la vida a un parlamentario y dejó herido a otro. El gobierno conservador de Mariano Ospina Pérez cerró el Congreso, de mayoría liberal, y el liberalismo, ya retirado del gobierno, que no contaba con garantías suficientes para acudir a las urnas, decidió no presentarse a las elecciones presidenciales de 1950; esta decisión obedeció, fundamentalmente, al hecho de que en una manifestación pública fue asesinado el hermano de Darío Echandía, quien era el candidato liberal a la presidencia de la República. 
En medio de esta confusa situación política y con la policía conservadora atacando poblaciones liberales, deteniendo y dando muerte a sus enemigos políticos, los mismos llaneros que se habían alzado contra el Pacificador Morillo, en Ios albores del siglo XIX, se levantaron en armas contra el gobierno conservador; estos grupos armados, organizados en 1949, no solamente eran conformados por liberales sino que, además, tenían el apoyo expreso o tácito de la Dirección Liberal, que veía en ellos una forma de presionar al gobierno para que cesaran los desmanes de la policía conservadora.

En 1950, sin la participación del liberalismo en la contienda electoral, llegó a la presidencia de Colombia Laureano Gómez, el más caracterizado representante de la derecha conservadora. Los campesinos liberales, en especial los de la región central del país, abandonaron sus pueblos para ocultarse en el monte, temerosos de la violenta represión del gobierno conservador. Después de un tiempo en el que se ocultaban durante el día y se movilizaban de noche en busca de sitios seguros, los campesinos decidieron organizarse en pequeños grupos para oponer resistencia armada a los agresores; esas primeras agrupaciones de defensa solían estar conformadas por grupos familiares que vivían en una misma región, de lo cual es ejemplo la conformada entonces por Pedro Antonio Marín (conocido como el "Comandante Tirofijo"), quien se organizó con 14 primos para enfrentar a los grupos conservadores violentos que contaban con el apoyo expreso o tácito del gobierno.

El hecho de que estos campesinos se hubieran organizado militarmente, ante todo para defender sus vidas, llevó al conocido penalista colombiano Alfonso Reyes a plantear en su tesis de grado al licenciarse como abogado, que las actuaciones de estos grupos guerrilleros podían ser cobijadas bajo la figura de una legítima defensa colectiva. Su organización como movimiento guerrillero los obligó a abandonar sus tierras, cuya propiedad perdieron porque fueron ocupadas por conservadores con el respaldo de la policía gubernamental, o porque se vieron obligados a venderlas en pésimas condiciones económicas ante la necesidad de huir de la violencia.

En 1952, los comandantes de los movimientos guerrilleros del centro del país convocaron a una Conferencia Guerrillera para intentar su agrupación en un solo movimiento de carácter nacional, bajo un mando unificado y con el expreso propósito de lanzar una ofensiva que les permitiera tomarse el poder. Las guerrillas liberales de Ios Llanos Orientales no acudieron unidas a la Conferencia Guerrillera, obedeciendo en ello instrucciones de una Dirección Liberal quizá temerosa de que una eventual ofensiva del movimiento guerrillero le diera vida independiente y lo pusiera fuera del control político que hasta ese momento ejercía sobre él. La Conferencia Guerrillera reconoció como su comandante en Jefe a Guadalupe Salcedo, uno de los líderes de la guerrilla llanera que no había asistido a la reunión, y decretó una reforma agraria democrática en virtud de la cual los comandantes guerrilleros podrían adjudicar tierras a miembros y simpatizantes de su causa.

Las guerrillas del centro de país, en especial las de las regiones del Tolima y Sumapaz, empezaron a ser permeadas por el comunismo, algunos de cuyos dirigentes las alentaban a recuperar sus tierras y organizarse en ellas de manera independiente. En los Llanos, la guerrilla liberal intentó financiarse a través de la creación de un impuesto revolucionario cobrado a los ganaderos a cambio de respetar sus tierras y sus vidas, lo que condujo a que éstos se organizaran militarmente para defenderse, dando nacimiento a lo que se conoció con el nombre de "guerrillas de paz". En las ciudades se agudizaban los enfrentamientos políticos, al punto que las casas de los más prestigiosos líderes del partido 
liberal (Alfonso López Pumarejo y Carlos Lleras Restrepo) fueron incendiadas por las turbas conservadoras, forzándolos a buscar asilo político en México.

En 1953, el presidente conservador Laureano Gómez intentó retirar del servicio al Comandante en Jefe del Ejército Nacional, general Gustavo Rojas Pinilla, quien se opuso y exigió que el gobierno fuera asumido por la figura del designado presidencial, el también conservador Rafael Urdaneta; al negarse este último a ejercer la presidencia, por temor a la reacción de Laureano Gómez, el general Gustavo Rojas Pinilla asumió directamente el poder con la aquiescencia del partido liberal y de una importante facción del partido conservador.

Con ese respaldo político, el general Rojas Pinilla propuso un gobierno de unión nacional, enarboló la bandera de la paz y consiguió que en los tres primeros meses de su gobierno se entregaran 6.500 guerrilleros de todo el país, entre los que se contaban 3.540 llaneros que entregaron sus armas siguiendo instrucciones de la Dirección Liberal que había ordenado la desmovilización de las guerrillas. Las guerrillas de influencia comunista, ubicadas en las regiones del Tolima y Sumapaz, ordenaron un cese al fuego, pero se negaron a entregar las armas, anunciando que permanecerían organizadas pero sin combatir, a la expectativa de las actuaciones del nuevo gobierno de derecha que representaba el general Rojas Pinilla.

Casi un año después de haberse producido estas masivas desmovilizaciones de la guerrilla, a través del Decreto 2184 de 1953, el gobierno de Rojas Pinilla concedió una amnistía para los miembros de la Fuerza Pública que hubieran sido procesados o condenados por delitos políticos y conexos, con anterioridad al 10 de julio de 1944, esto es, por hechos ocurridos antes del intento de golpe de Estado que se intentó en Pasto con- tra el presidente López Pumarejo. Posteriormente, a través de los Decretos 1823 y 2062 de 1954 se concedieron dos nuevas amnistías que comprendieron los hechos ocurridos durante esa última década y que estaban dirigidas tanto a civiles como a militares. Con la finalidad de poder cobijar con la amnistía a la policía que había agredido a los campesinos liberales y a las denominadas "guerrillas de paz" que combatían a las guerrillas liberales de los Llanos, el Decreto 2062 de 1954 ampliaba el concepto de delito político en los siguientes términos: "Para los efectos del presente decreto se entiende por delitos políticos todos aquellos cometidos por nacionales colombianos cuyo móvil ha sido primero el ataque al gobierno o que puedan explicarse por extralimitación en el apoyo o adhesión a éste o por aversión al sectarismo político".

En las regiones del Tolima y Sumapaz, las guerrillas de influencia comunista se organizaron políticamente sin abandonar las armas, trabajando la tierra de manera colectiva y difundiendo entre sus partidarios las ideas socialistas; los principales líderes de estos movimientos sociales fueron Juan de la Cruz Varela y "Tirofijo". Frente a esta situación, el gobierno de Rojas Pinilla declaró ilegal el comunismo y ordenó ejecutar operaciones militares de "tierra arrasada" en municipios como Planeta Rica y otros de marcada influencia guerrillera; por su parte, los políticos conservadores, avalados por unas fuerzas militares y un gobierno que cada día trabajaba más cerca de los conservadores que de los liberales, empezaron a estimular la represión porque intuían un enemigo peligroso en esas guerrillas que se negaban a hacer entrega de sus armas.

Si se entiende que las amnistías promulgadas por Rojas Pinilla iban dirigidas de manera exclusiva a poner fin a la violencia partidista, proponiendo un gobierno en el que tuvieran igualdad de garantías los partidos liberal y conservador, se podrá explicar la actitud de las guerrillas co- 
munistas de la época, al negarse a entregar las armas y permanecer organizadas políticamente en sus regiones. Ellas no se acogieron a la amnistía, por la sencilla razón de que no fue diseñada para la guerrilla comunista que propugnaba por un modelo político diverso, sino que fue concebida para permitir el retorno de las guerriIlas liberales a la institucionalidad de su partido y a la contienda electoral dentro del mismo modelo social y político imperante en el país. Por eso, las guerrillas comunistas, si bien cesaron en sus actividades armadas, se organizaron en sus regiones de influencia bajo un modelo político que rápidamente fue considerado ilegal por el gobierno, con el apoyo tanto del partido conservador como del partido liberal que vieron a estos grupos como una amenaza a la vigencia del modelo social y político imperante en Colombia.

Aun cuando invocando la existencia de un "Binomio Pueblo-Fuerzas Armadas", que parecía ajeno a los partidos tradicionales, el general Rojas Pinilla seguía gobernando cada vez más cerca del conservatismo y comenzó una política de represión que incluyó un ataque de las Fuerzas Militares a la región del Sumapaz, donde permanecían organizados los miembros de las guerrillas comunistas al mando de Juan de la Cruz Varela, pero en actitud pacífica. La guerrilla opuso una fuerte resistencia al avance del Ejército, que comenzó a desplazar campesinos para poder combatir de manera más efectiva a la guerrilla y organizó en el municipio de Cunday un campo de concentración para enemigos del régimen. Esta guerrilla, lejos de ser militarmente derrotada, escapó al cerco del ejército y se reubicó territorialmente. Los "pájaros", una suerte de sicarios organizados por algunas direcciones regionales del partido conservador (que sirvieron de inspiración al escritor Gustavo Álvarez Gardeazabal para escribir su novela Cóndores no entierran todos los días), sembraron el terror en el Valle del Cauca mediante la persecución sistemática y eliminación física de los liberales. La ola de represión desatada por el gobierno de Rojas Pinilla terminó en 1957 con un paro nacional organizado por los industriales y respaldado por liberales y conservadores, que le llevó a abandonar el poder a favor de una Junta Militar designada por él mismo. Durante el corto tiempo en que esta Junta Militar gobernó, se persiguió y dio muerte a Guadalupe Salcedo, el legendario Comandante en Jefe de las Guerrillas del Llano que se había acogido a la amnistía de Rojas Pinilla; esta muerte llevó a que muchos de los guerrilleros desmovilizados temieran por sus vidas y regresaran a la lucha armada clandestina.

Los jefes de los partidos liberal y conservador. Alberto Lleras Camargo y Laureano Gómez, respectivamente, se reunieron en las ciudades españolas de Sitges y Benidorm y acordaron que, para poner fin a la prolongada violencia política, sus movimientos políticos se alternaran en el ejercicio del poder durante los siguientes 16 años; durante ese período, sólo podrían competir por la presidencia de la República, y de manera alternada, los liberales y los conservadores, correspondiendo el primer gobierno al partido liberal. Nació así la figura conocida en Colombia con el nombre de Frente Nacional; los cargos de importancia dentro de cada gobierno deberían ser repartidos de manera equitativa entre miembros de los partidos liberal y conservador, lo cual incluía al poder judicial; así, la mitad de los jueces del país debían ser liberales y la otra mitad conservadores, desde el juzgado del más pequeño municipio del país hasta la Corte Suprema de Justicia. Si bien este gran acuerdo permitía superar una época de cruda violencia partidista, no puede desconocerse que la acordada alternancia de los partidos liberal y conservador en el gobierno cerró las posibilidades de acceso al poder a todos aquellos que no pertenecieran a esas agrupaciones políticas, situación que desde el comienzo supuso negarle toda posibilidad de participación en política a las guerrillas comunistas que, a pesar de estar desmovilizadas, insis- 
tían en la implantación de un régimen socialista, cuando menos en sus regiones de influencia.

El primer gobierno liberal del denominado Frente Nacional correspondió al liberal Alberto Lleras Camargo, quien invitó a la desmovilización de los grupos armados, concediendo una amnistía en la que se conservaba la definición amplia de delito político utilizada por Rojas Pinilla, con el fin de permitir que se acogieran a ella tanto quienes habían combatido contra el gobierno como quienes habían luchado por defenderlo; la amnistía consagraba la suspensión de los procesos e imponía a los amnistiados la prohibición de residir en determinados sitios del territorio nacional. A esta amnistía no se acogieron las guerrillas comunistas, dado que tampoco estuvo concebida para ellas, sino para quienes en nombre de los partidos liberal y conservador se habían enfrentado por el gobierno; los comunistas, desde la vigencia misma del Frente Nacional, habían quedado sin ninguna opción de participar activamente en la política del país, salvo que renunciaran a sus ideas y se plegaran a alguno de los dos partidos tradicionales: el liberal o el conservador.

Buena parte de los integrantes de las guerrillas liberales desmovilizadas fueron incorporados a la policía y, dentro de ella, combatieron a las guerrillas comunistas que, una vez más, se haIlaban desmovilizadas y organizadas políticamente en sus regiones, sin haber hecho entrega de sus armas al gobierno. Los dirigentes conservadores comenzaron a denunciar desde el Congreso la existencia de "Repúblicas Independientes", como la de Marquetalia, en las que regiría un sistema político y social diverso al resto del país y el Ejército no tendría autoridad debido a que se trataba de comunidades organizadas que jamás habían entregado sus armas. La policía, con ayuda de los antiguos guerrilleros liberales, dio muerte a Charro Negro, uno de los líderes de las guerrillas comunistas que vivía con cerca de 40 hom- bres más en la región de Marquetalia; esto constituyó el primer ataque directo del gobierno a las regiones donde la guerrilla comunista ejercía su influencia. Posteriormente, el gobierno cedió de manera definitiva a la presión de los conservadores y ordenó ataques militares a las denominadas "Repúblicas Independientes", comenzando por Marquetalia donde se enfrentaron 16.000 hombres del ejército contra 44 guerrilleros que opusieron una feroz resistencia aprovechando su conocimiento del terreno.

Frente a estos ataques de las tropas gubernamentales, los pequeños movimientos guerrilleros que poblaban las cinco "Repúblicas Independientes" de las que por aquella época se hablaba (Marquetalia, Riochiquito, Pato, Guayabero y Cimacota) decidieron reunirse y formar un grupo común que les permitiera hacer frente a las Fuerzas Militares. Nacen en ese momento, 1964, de manera formal, las Fuerzas Armadas Revolucionarias de Colombia (FARC) al mando de un antiguo guerrillero liberal: Pedro Antonio Marín, conocido como Manuel Marulanda Vélez o Tirofijo.

En 1966, bajo la influencia de la Revolución Cubana, nació en Colombia un nuevo movimiento guerrillero, el Ejército de Liberación Nacional (ELN), del que formaba parte el sacerdote español Manuel Pérez y más tarde el religioso colombiano Camilo Torres y el también sacerdote español Domingo Laín. En la misma década del 60 se produjo una división al interior del partido comunista, propiciada por quienes no compartían el hecho de que las guerrillas se hubieran desmovilizado en los años 1953 y 1954 en vez de haber permanecido en pie de lucha contra el régimen. Se funda así el Partido Comunista Marxista Leninista y, de manera simultánea, se crea el Ejército Popular de Liberación (EPL) como un movimiento guerrillero expresamente destinado a ser el brazo armado del recién creado partido político; su nacimiento se produce en el departa- 
mento de Córdoba, en la costa norte colombiana, en 1967, durante la vigencia del Frente Nacional.

Para el último período presidencial del Frente Nacional, 1970 a 1974, el turno de gobernar le correspondía al partido conservador que, en ejercicio de ese derecho, presentó cuatro candidatos a la presidencia. De manera sorpresiva, y en clara contraposición con lo acordado por los partidos liberal y conservador, un importante sector de la opinión pública decidió lanzar la candidatura presidencial del general Rojas Pinilla bajo las banderas de un nuevo movimiento político al que denominó la Alianza Nacional Popular (ANAPO). Para sorpresa del país, el 19 de abril de 1970, día señalado para las elecciones, la afluencia de anapistas a las urnas fue enorme $y$, cerca de la medianoche, los escrutinios parciales daban como ganador, con una mayoría considerable sobre los cuatro candidatos conservadores, al general Rojas Pinilla. El presidente de turno, el liberal Carlos Lleras Restrepo, ordenó suspender la transmisión radial de los boletines electorales y al amanecer del 20 de abril de 1970 anunció públicamente que el ganador de las elecciones había sido el conservador Misael Pastrana Borrero.

Los anapistas consideraron desde entonces (y en eso los respalda buena parte de la opinión pública) que lo que hubo el 19 de abril de 1970 no fue nada diverso a un fraude electoral patrocinado por los partidos liberal y conservador para preservar la vigencia del Frente Nacional e impedir que pudiera acceder al poder un partido político diverso del liberal o el conservador, en especial si se trataba de un movimiento liderado por el ex dictador al que habían derrocado doce años atrás. El 19 de abril de 1973, un pequeño grupo armado penetró a la Quinta de Simón Bolívar en Bogotá y robó una espada del libertador; los autores de este hecho se autodenominaron Movimiento 19 de Abril (M-19) y anunciaron que man- tendrían en su poder la espada como símbolo de su lucha armada, porque entendían que el pueblo sí puede llegar al poder a través de las urnas, como lo hizo la Anapo en 1970, pero no se puede mantener en él sin la ayuda de las armas.

El M-19 comenzó sus actividades como un grupo guerrillero predominantemente urbano, que realizaba espectaculares acciones en las ciudades para crear conciencia y obtener apoyo popular; así, por ejemplo, respaldó las huelgas de los movimientos sindicales, robó camiones de leche y alimentos para repartirlos en barrios populares, etc. Durante el gobierno del liberal Julio César Turbay, entre 1978 y 1982, se desató una de las oleadas de mayor represión en Colombia, caracterizada por el frecuente empleo de la tortura, las desapariciones y los asesinatos selectivos de activistas de izquierda. El M-19, en su afán por poner en evidencia los altos niveles de represión del gobierno, realizó nuevas acciones espectaculares como el robo de varios miles de armas que los militares tenían en un depósito de Bogotá y la toma de la Embajada de la República Dominicana en Bogotá, en la que por primera vez plantearon la necesidad de un diálogo nacional sobre los problemas del país; este último episodio culminó cuando el M-19 recibió USD \$1'000.000,00 (al parecer provenientes de gobiernos extranjeros, cuyos diplomáticos estuvieron retenidos en la mencionada sede diplomática), autorización para viajar a Cuba y la promesa de recibir la visita de un delegado de Amnistía Internacional, cuyo informe negativo sobre la situación de los derechos humanos en el país sería más tarde rechazado por el gobierno. Al final de su período presidencial, Turbay propuso una amnistía que no cobijaba casi ningún delito conexo y brindaba tan pocas garantías que prácticamente no tuvo efectos prácticos; en ella, se consagraba que quien quisiera acogerse a la amnistía debía presentarse, identificarse y entregar las armas, condiciones que no 
daban seguridad a quienes, habiendo escogido el camino de la lucha guerrillera, habían padecido la represión militar impulsada por ese gobierno.

En 1982 llegó a la presidencia de la República Belisario Betancur, enarbolando la bandera de la paz; desde allí propuso una amnistía que comprendía casi todos los delitos conexos con los políticos, a excepción de los cometidos fuera de combate y con indefensión de la víctima, con lo que se pretendía no dejar en la impunidad el reciente homicidio del ex ministro Rafal Pardo Buelvas, asesinado por un comando guerrillero en su propia casa. La amnistía ofrecida operaría sin necesidad de que los guerrilleros se presentaran a la justicia y admitieran sus delitos y no los obligaba a entregar las armas. Con esta amnistía, quedaron en libertad algunos de los líderes del M-19 que habían sido capturados, y se reincorporaron a la vida civil algunos insurgentes, en especial de ese movimiento guerrillero que, por aquel entonces, se encontraba muy golpeado por acciones en las que había perdido muchos de sus hombres, como la desplegada por el Ejército como consecuencia del robo de las armas en el Cantón Norte y una sorpresiva operación de las fuerzas de seguridad del Estado que impidió la entrada de un gran número de armas al país a bordo del barco El Karina.

En 1984, después de promulgada dicha amnistía y pese a sus escasos resultados en cuanto a la entrega de guerrilleros, el gobierno avanzó en la búsqueda de una solución negociada al conflicto, intentando conversaciones de paz con las FARC; como resultado de estos primeros contactos, este grupo guerrillero ordenó un cese unilateral al fuego y condenó públicamente el secuestro, la extorsión y el terrorismo como formas de lucha revolucionaria; a las pocas semanas, el gobierno ordenó un cese al fuego para corresponder a la actitud de las FARC. En el mismo contexto, el presidente Betancur se entrevistó en Madrid con líderes del M-19 y junto con el EPL sus- cribió nuevos acuerdos de paz en los que las partes se comprometieron a mantener un cese al fuego y a tomar parte en un gran diálogo nacional.

Las conversaciones se adelantaban con extrema lentitud, el Congreso tardaba en la aprobación de reformas políticas acordadas con la guerrilla y con relativa frecuencia se producían enfrentamientos armados entre Ejército y guerrilla, que cada una de las partes atribuía a la violación unilateral de la tregua por parte de la otra. El 6 de noviembre de 1985, un comando armado del M-19 se tomó el Palacio de Justicia en Bogotá, y el presidente Betancur ordenó o consintió que el Ejército iniciara una operación militar con la ayuda de tanques, para retomar por la fuerza un edificio que, ya incendiado y en ruinas, escondía bajo sus cenizas un centenar de cadáveres, entre ellos los de la mitad de los magistrados de las altas cortes. Fue el comienzo del fin de la paz ofrecida por el presidente Betancur.

Quienes siendo militantes de las FARC se desmovilizaron y acordaron la creación de un partido político denominado Unión Patriótica fueron víctimas de una prolongada y sistemática cacería (detrás de la cual estaban grupos paramilitares aliados con poderosos narcotraficantes), en la que cientos de ellos murieron asesinados, incluidos varios de sus candidatos a la presidencia de la República. El EPL recrudeció sus acciones en la costa norte de Colombia, lo que movió a algunos de los ganaderos de la zona a organizarse en grupos paramilitares para suplir la ausencia de la fuerza pública. Una vez más, se comenzó por pequeñas agrupaciones familiares, como la de los hermanos Castaño, que poco a poco fueron creciendo para proteger propiedades diversas de las suyas y que finalmente decidieron pasar a la ofensiva creando un gran ejército para perseguir a la guerrilla; hoy, se calcula que cerca de $\mathbf{1 2 . 0 0 0}$ hombres militan en los grupos paramilitares, combatiendo a cerca de 20.000 guerrilleros en todo el territorio nacional. 
El M-19, derrotado militarmente y con escaso apoyo popular, consiguió una amnistía y sus principales dirigentes se incorporaron a la vida nacional, donde han conseguido acceder a algunas alcaldías y a varios escaños en el Congreso, no sin que algunos de sus dirigentes hayan sido víctimas de atentados como el que le costó la vida a su primer candidato presidencial, Carlos Pizarro. Desde esta perspectiva, bien podría decirse que el M-19 consiguió uno de sus principales propósitos: el acceso a la contienda democrática y el respeto a sus resultados electorales.

Entretanto, se produjo en Colombia el auge del narcotráfico y sus grandes jefes comenzaron a recurrir a la guerrilla como un expedito mecanismo para mantener vigilados sus cultivos de coca y las pistas clandestinas que facilitaran la distribución de la droga. Surgió así una alianza en la que las dos partes se beneficiaban, pues mientras los narcotraficantes disponían de un gran ejército que cuidaba sus cultivos, sus laboratorios de producción y sus pistas clandestinas, la guerrilla cobraba un porcentaje sobre cada kilo de cocaína que se sacara de sus zonas de influencia. Sin embargo, no tardaron en surgir diferencias entre guerrilleros $y$ narcotraficantes, que desembocaron en la formación de ejércitos particulares de los narcotraficantes que, engrosando las filas del paramilitarismo, comenzaron a luchar contra los grupos guerrilleros.

Endurecida la lucha del Estado contra los narcotraficantes a comienzos de los años noventa, cayeron abatidos dos de sus principales jefes: Pablo Escobar Gaviria y Gonzalo Rodríguez Gacha, justamente quienes más se habían servido de los grupos guerrilleros para la vigilancia de sus propiedades y quienes más duramente habían terminado combatiéndolos. Este desenlace de la lucha contra el narcotráfico dejó a la guerrilla en posesión de los más importantes cultivos de coca en el país, con abundantes laboratorios para procesar cocaína, infinidad de pistas para su exportación y sin el acoso de los narcotraficantes. Empezó así para la guerrilla una época de gran abundancia económica y de rápido crecimiento en número de combatientes y en calidad de armamento y preparación militar. Algunos grupos paramilitares, buscando un desarrollo económico que les permitiera combatir a la guerrilla en igualdad de condiciones, incursio-naron también en el negocio del narcotráfico, primero como protectores de los cultivos, laboratorios y pistas clandestinas y posteriormente como productores y exportadores de la droga.

En vísperas de las elecciones presidenciales de 1998, el entonces candidato a la presidencia Andrés Pastrana Arango se entrevistó con Tirofijo (comandante máximo de las FARC) y dejó en el electorado la sensación de que, si resultaba elegido presidente, podría conseguirse la paz con los grupos guerrilleros. Una vez en el poder, Pastrana Arango acordó con las FARC la creación de una "zona de distensión" en la que pudieran llevarse a cabo las conversaciones de paz; cuando se pensaba que se trataría de una pequeña zona en la que no habría presencia del Ejército para facilitar el desplazamiento de los guerrilleros que tomaran parte en las negociaciones, las FARC solicitaron y obtuvieron que el territorio despejado fuera de aproximadamente 42 mil kilómetros cuadrados, y que allí no hubiera ninguna autoridad del Estado: ni militares, ni policías, ni alcaldes, ni fiscales ni jueces. La guerrilla obtuvo así un territorio en el que podían cultivar libremente coca, procesarla y exportarla, así como refugiarse impunemente después de sus acciones militares, pues el Ejército sólo podía perseguirles hasta los límites de la zona de distensión. En vista de que durante todo el tiempo en que duraron las conversaciones de paz los grupos guerrilleros no sólo no cesaron en sus actividades al margen de la ley, sino que, por el contrario, incrementaron en forma notable los ataques a poblaciones y los secuestros, al final de su gobierno el presidente Pastrana dio por terminada la zona de distensión que había creado para adelantar las conversaciones de paz. 
Esta serie de situaciones cambió radicalmente la percepción que la opinión pública nacional tenía sobre el problema guerrillero, lo que en el 2002 condujo a que se eligiera como presidente al liberal Álvaro Uribe Vélez, quien inició una fuerte ofensiva militar en contra de la guerrilla. No obstante, el presidente Uribe Vélez siempre ha sostenido que no es enemigo del diálogo con los grupos armados y que estaría dispuesto a tomar parte en un proceso de paz, siempre que ello no suponga ceder la soberanía sobre territorio alguno del Estado ni dejar de combatir una guerrilla que se mantiene en actitud beligerante.

En ese contexto, a finales de 2003 se presentó al Congreso un proyecto de ley en el que se proponía la suspensión condicional de la ejecución de la pena para "miembros de grupos armados organizados al margen de la ley, cuando se encuentre comprometida la paz nacional". Esa suspensión condicional de la pena tendría una duración máxima de cinco años, después de los cuales podría convertirse en libertad definitiva, siempre que el condenado cumpla con las condiciones que le hayan sido impuestas.

El proyecto de ley hace una amplia referencia a los grupos alzados en armas, al estilo de las definiciones abiertas que de delito político se utilizaron en las amnistías de 1954, para así facilitar los procesos de paz no sólo con los movimientos guerrilleros, sino con los grupos paramilitares; la concesión de la suspensión condicional de la ejecución de la pena, que operaría sólo a petición directa y discrecional del Presidente de la República, estaría limitada a los eventos en los que se encontrara comprometida la paz nacional, con lo que se excluiría de este beneficio a grupos armados que desarrollan actividades de delincuencia común.

No se prevé la entrega de armas por parte de los grupos armados, dado que históricamente se ha demostrado la inutilidad de esta exigencia; así lo pusieron de presente varios grupos guerrilleros que en la década del 50 entregaron una parte insignificante de sus armas, conservando no sólo la mayor parte de ellas, sino las de mejor calidad.

El hecho de que la propuesta se concrete en una suspensión condicional de la ejecución de la pena permite que se ejerza el derecho que las víctimas y la comunidad tienen a conocer la verdad sobre los hechos de violencia que las han afectado. Una comunidad social no puede renunciar al derecho de conocer los hechos violentos de que ha sido víctima ni al de incorporarlos a su historia; por eso, es importante que en este proyecto de ley esté previsto que quienes quieran acogerse a sus beneficios, deban ser previamente condenados por los delitos que han cometido, bien sea porque los admiten voluntariamente o porque se demuestra su participación en ellos sin que lo acepten de manera expresa.

Pero este proyecto de ley no sólo consagra el derecho de saber, sino también el derecho a la justicia, pues sólo prevé la suspensión condicional de la ejecución de la pena para quien, habiendo sido condenado por sus delitos, tome parte de manera activa en un proceso de paz. Finalmente, se consagra en el mencionado proyecto el derecho a la reparación de las víctimas, a través de mecanismos como la realización de trabajo social a favor de la recuperación de las víctimas, la colaboración activa y efectiva con instituciones que se dediquen al trabajo social por la recuperación de las víctimas, el aporte de bienes a instituciones que se dediquen al trabajo social por la recuperación de las víctimas, la entrega de bienes al Estado para la reparación de las víctimas, la colaboración activa y efectiva en la desmovilización de organizaciones armadas al margen de la ley, la colaboración eficaz al esclarecimiento de los hechos ocurridos con ocasión del conflicto o el aporte de información que contribuya eficazmente a la desarticulación de grupos organizados al margen de la ley. 
Cuando Colombia ratificó la creación y puesta en funcionamiento de la Corte Penal Internacional, se dijo que ello podría dificultar la realización de un proceso de paz, debido a que la Corte posee competencia para el juzgamiento de crímenes de guerra como los cometidos por los grupos colombianos alzados en armas. Para hacer frente a esta eventualidad, el gobierno colombiano se acogió a una disposición transitoria consagrada en el artículo 124 del Estatuto de Roma, que prevé la posibilidad de que un Estado pueda declarar que, "durante un período de siete años contados a partir de la fecha en que el Estatuto entre en vigor a su respecto, no aceptará la competencia de la Corte sobre la categoría de crímenes a que se hace referencia en el artículo 8" (crímenes de guerra), "cuando se denuncie la comisión de uno de esos crímenes por sus nacionales o en su territorio".

Dado que el artículo 124 del Estatuto de Roma prevé un aplazamiento de la fecha a partir de la cual la Corte Penal Internacional tendría competencia para el juzgamiento de algunos crímenes de guerra, el invocar esa disposición, como lo ha hecho el gobierno colombiano, no garantiza que los crímenes de guerra ya cometidos por los grupos alzados en armas o los que ocurran en los próximos siete años no puedan ser objeto de juzgamiento. Por el contrario, lo que de esta norma se desprende es que, transcurridos Ios siete años en ella consagrados, la Corte Penal Internacional adquiere plena competencia respecto de esos delitos y que, al ser ellos imprescriptibles, podrán ser objeto de juzgamiento, con absoluta independencia del momento en que ellos hayan tenido ocurrencia. Cosa bien distinta es que la Corte Penal Internacional decida asumir el juzgamiento de esos delitos pese a la existencia de un eventual proceso de paz como el que se propone ahora en Colombia.

La Corte Penal Internacional podría admitir que, pese a la suspensión de la ejecución de la sen- tencia, lo evidente es que los alzados en armas fueron juzgados y condenados por sus delitos, que se respetó el derecho que la comunidad tiene a conocer la verdad, que se aplicó el derecho a la justicia y que se respetó el derecho a la reparación que tienen las víctimas. Frente a esta realidad, es factible que la Corte Penal Internacional se abstenga de iniciar juicios en contra de quienes se han acogido a un proceso de paz como el que ahora se propone en Colombia, pues una decisión en sentido contrario no sólo supondría el desconocimiento de la voluntad de un pueblo soberano, sino que podría generar reparos sobre la legitimidad y la autoridad que debe rodear un organismo como la Corte Penal Internacional.

Quizás el aspecto más complicado de un proceso de paz como el que se busca en Colombia es el relacionado con que el Estado pueda ofrecer en el futuro a los desmovilizados; los anteriores procesos de paz adelantados en nuestro país han puesto de presente que si los alzados en armas no encuentran una solución aceptable a los problemas que los llevaron a la lucha armada, no tendrán ningún aliciente para abandonarla. Por eso, se hace indispensable no sólo garantizar hacia el futuro la participación activa de los desmovilizados en las contiendas electorales, sino el mejoramiento de las condiciones de vida en muchas regiones del país que hoy viven en precarias condiciones económicas. Pero, además, los desmovilizados deben encontrar posibilidades de incorporarse al mercado laboral para garantizar su propia subsistencia y la de sus familias, lo cual no es tan sencillo de conseguir en un país con una tasa de desempleo cercana al veinte por ciento $(20 \%)$, sin seguro de desempleo y con falencias en la prestación de servicios médicos básicos a quienes carecen de medios económicos para pagarlos. Por lo demás, si se privilegiara a los desmovilizados mediante la obtención de empleo, se estaría enviando un mensaje equivocado a quienes siempre se han 
mantenido dentro de la legalidad, pues verían que tienen más facilidad de acceso al mercado laboral quienes se han alzado en armas contra el gobierno y atacado la sociedad, que aquellas personas que siempre han respetado las normas.

Este breve recuento de la lucha armada en Colombia y de los varios intentos que se han hecho para conseguir la paz nos indica que las causas de nuestros conflictos han sido diversas; que la lucha guerrillera ha cambiado con el transcurso de los años y que, por consiguiente, sólo se puede hacer la paz si se tienen en cuenta las razones de fondo que dieron origen a la lucha armada y se les busca una adecuada solución. Los problemas meramente técnico-jurídicos, como el alcance del concepto de delito político, la determinación de los delitos conexos que puedan ser objeto de una amnistía o la competencia de la Corte Penal Internacional, son relativamente sencillos de superar. Pero si no se eliminan o morigeran las causas que han dado origen a los actuales grupos guerrilleros y paramilitares, las amnistías sólo conseguirán una momentánea disminución cuantitativa del problema, pero no lograrán que los grupos alzados en armas desaparezcan del escenario nacional.

Lo curioso es que en Colombia los procesos de paz siempre han comenzado por la concesión de amnistías, esporádicamente han alcanzado acuerdos de cese al fuego y raramente han llegado a la formulación y puesta en práctica de mecanismos que permitan eliminar las causas estructurales que han dado origen al surgimiento de los grupos guerrilleros y paramilitares. Quienes más cerca se muestran actualmente de un proceso de paz son estos últimos, pues en la medida en que el Estado ha venido recuperando el control militar sobre el territorio nacional, empiezan a desaparecer las razones que dieron origen al movimiento paramilitar. Brindarle una solución al problema guerrillero es, en cambio, mucho más difícil porque al componente meramente ideológico de grupos como las FARC o el ELN, se suma su íntima vinculación con el fabuloso negocio del narcotráfico, que les ha proporcionado enormes cantidades de dinero. Pero si el proceso de paz no sirve para la incorporación del movimiento guerrillero a la vida social, entonces quedará nuevamente abierta la puerta para la conformación de grupos paramilitares que busquen la eliminación del movimiento guerrillero por la vía de las armas, y la violencia en Colombia habrá comenzado un nuevo ciclo.

\section{BIBLIOGRAFÍA}

ÁLAPE, Arturo. El Bogotazo: memorias del olvido, Bogotá: Fundación Universidad Central, 1983.

ÁLAPE, Arturo. La paz, la violencia: testigos de excepción. Bogotá: Editorial Planeta, 1985.

ECHEVERRI URUBURU, Álvaro. Élites y proceso político en Colombia. $2^{\text {a }}$ edición. Bogotá: Fundación Universidad Autónoma de Colombia, 1997.

GUZMÁN CAMPOS, Germán; FALS BORDA, Orlando y UMAÑA LUNA, Eduardo. La violencia en Colombia: estudio de un proceso social. Segunda edición, Bogotá: Ediciones Tercer Mundo, 1962, Tomo I.

La violencia en Colom-

bia: estudio de un proceso social. Bogotá: Círculo de Lectores, 1988, Tomo II.

MONCADA, Alonso.Un aspecto de la violencia. Bogotá: Promotora Colombiana de Ediciones y Revistas Ltda., 1963. 